\title{
Issue expertise in policymaking
}

\author{
PETER J. MAY \\ Department of Political Science, University of Washington, USA \\ E-mail: pmay@uw.edu \\ CHRIS KOSKI \\ Department of Political Science, Reed College, USA \\ E-mail: ckoski@reed.edu \\ NICHOLAS STRAMP \\ Department of Political Science, University of Washington, USA \\ E-mail: stramp@uw.edu
}

\begin{abstract}
In considering issue expertise in policymaking, we unpack differences in the supply and types of expertise with attention to the presumed privileged role of the bureaucracy. Our empirical investigation is based on witness testimonies of congressional hearings for a policy area involving various forms of expertise - critical infrastructure protection policymaking. Three sets of findings stand out. One set substantiates the role of the bureaucracy as an important information conduit while also showing it is not a primary source of issue expertise. A second set shows how differences in issue maturity and salience affect the demand for and supply of expertise. A third set illustrates the influence of a small cadre of hyper-expertise in drawing attention to problems and solutions across different venues. These findings challenge the conventional view of the bureaucracy in policymaking while expanding the understanding of different sources of information and types of issue expertise in policymaking.
\end{abstract}

Key words: bureaucracy, issue expertise, policymaking, public risks

\section{Introduction}

Among other sources of the seemingly endless supply of information in policymaking, the bureaucracy has historically been considered a privileged information source. In recognising the growth of alternate information sources, public administration scholars have questioned the extent that United States (US) policymakers rely on the bureaucracy for issue expertise. Francis Rourke (1991) first observed how the rise of public interest and other advocacy groups challenges the role of bureaucratic expertise in policymaking. In extending Rourke's observation, Robert Durant (1991, 471) argues that bureaucratic influence has been transformed as "actors are more numerous, 
expertise is more diffused, and conflict is more rampant". Similarly, Lee $(2013,1)$ argues that "the monopoly of bureaucratic expertise has been undermined as interest groups have significantly developed and are professionalized".

In setting forth an agenda for research on an information processing theory of policymaking, Workman, Jones and Jochim (2009) call for empirical research about the role of the bureaucracy as an information conduit for policymaking. More generally, different sources of information tend to be lumped together in addressing how policymakers process an oversupply of information (Jones and Baumgartner 2005). Our examination of issue expertise in policymaking helps to unpack these by getting at differences in the supply and types of information in policymaking. Consideration of this also extends thinking about sources of expertise beyond scientific and research experts (Weible 2008), as advanced with recent scholarship concerning the political economy of expertise in American policymaking (Esterling 2004; Hall and Deardorff 2006; Bertelli and Wenger 2009; Gailmard and Patty 2013).

Four sets of issues need to be addressed when considering bureaucratic and other sources of issue expertise in policymaking. One is the nature of expertise as it relates to substantive knowledge about a given set of issues. The literature on expert-based information in policymaking highlights the importance of credibility (Howlett 2009; Montpetit 2011) and objective knowledge of issues (Keller 2009). Simply labelling one an expert or having academic credentials or an affiliation with a think tank or other seemingly authoritative organisation does not guarantee expertise for a particular set of policy issues. Talk shows and other media are full of pseudo-experts. In this regard, an important distinction can be made between issue expertise as it relates to substantive knowledge of problems and solutions and other forms of information provision. The latter include drawing attention to issues and reporting on the status of conditions or actions to address a problem.

A second issue concerns potential sources of expertise. The growth of think tanks, advocacy groups, analytic organisations and other information sources suggests a variety of sources of information that run the gamut of issue advocacy, reporting and issue expertise. As such, it is inappropriate to think of a distinguishable category of experts without considering the issues at hand and the nature of the information being provided. This is a central point of Esterling's (2004) study of "public-interested policy expertise" (p. 10) in which he portrays the provision and use of information by interest groups as highly contingent (also see Hall and Deardorff 2006). Issue expertise may come from those in academic settings, the bureaucracy, industry, professional associations and think tanks, among other sources. At the same time, individuals from such organisations who seek to influence policymaking do so through a combination of issue advocacy, informational reporting and 
substantive advice about problems and solutions. Not all instances of information provision can be considered provision of issue expertise.

A third issue concerns the availability of issue expertise. Despite the explosion of information sources in policymaking, not all problems have a readymade supply of issue experts who are willing and able to add helpful information in terms of problem definitions or policy solutions. Theories about interest involvement suggest that the demand and supply of issue expertise is shaped by issue salience and issue niches (Gray, Lowery, Fellowes and Anderson 2005; Leech et al. 2005). Issues with low political salience often generate insufficient political attention to motivate a supply of information from advocacy organisations, thereby privileging bureaucratic expertise in policymaking for such issues (May 1991). Groups and, by extension, different types of issue expertise are drawn into policy discussions as issues gain prominence and have demonstrated material and other interest-specific consequences. As issues demand attention, those with the largest stakes at hand are drawn into policy debates. Who these are depends on the specifics of the issues.

A fourth issue is the degree to which issue expertise helps advance policymaking. One of the underlying assumptions of expert-based policymaking is that expertise is a harmonising force - that is, policy expertise moves policy discussions from unfocused debates about what a policy is or should be to more focused debates about components of particular policies. However, this assumption does not necessarily apply in cases where different experts disagree (Weible 2008; Keller 2009; Montpetit 2011) or when experts are called upon to testify in multiple venues about the same problem.

These four sets of issues frame our investigation of issue expertise in policymaking. We address the sources of expertise in policymaking for a particular issue area with attention to how information sources differ in terms of types of information, issue sub-areas and across different venues. We develop these considerations further by providing specific hypotheses about each. Our empirical investigation is based on data about information provision for a policy area - Critical Infrastructure Protection (CIP) - for which bureaucratic expertise can be expected to dominate policymaking. CIP concerns the security of key resources held by public and private entities critical to American security, the economy or way of life (US Department of Homeland Security 2006, 2009). The distinction between non-cyber-related CIP issues and cyber-related CIP issues is useful for examining the consequences of differences in the availability of issue expertise. The former have a less developed supply of interest organisations and issue engagement, while the latter has drawn greater attention among industry and other organisations. 


\section{Hypotheses about issue expertise in policymaking}

The preceding introductory comments draw attention to different considerations about issue expertise in policymaking. The following hypotheses sharpen these with attention to the roles of bureaucratic expertise, different issue sub-areas and venues.

\section{Bureaucratic expertise and policymaking}

(H1) : Bureaucratic expertise dominates other sources of expertise.

Issue experts are called upon by committees in Congress to both help diagnose problems and to offer potential solutions. Two contending views exist with respect to the pervasiveness of bureaucratic expertise in this setting. One is that the bureaucracy has both a defined role and advantages as a source of issue expertise. More than mere implementers of policy, the federal bureaucracy serves as the "antennae of government" - to use Workman's (2014) depiction of the bureaucracy in monitoring issue areas and calling attention to emergent problems (also see Palus and Yackee 2013). From this perspective, bureaucrats are credible sources of expertise with well-established relationships with different congressional committees who serve as conduits of information.

Miller's (2004) research about the criminal justice subsystem provides support for the dominance of bureaucratic actors, finding a strong presence for "federal, state and local criminal justice bureaucrats" at crime-related congressional hearings (30-40\% of all witnesses) with much less involvement from citizen or community groups. In illustrating a more substantive role for bureaucrats in policymaking, Christensen (2012) discusses how neo-liberal tax reform in the 1980s and 1990s in New Zealand was facilitated by "autonomous bureaucratic action" that involved bureaucratic articulation of key ideas and advocacy for their adoption.

A counter to the bureaucratic dominance hypothesis is that the proliferation of advocacy organisations, think tanks, professional associations and other information provides a set of voices that can drown out the bureaucracy in policymaking (Durant 1991; Rourke 1991). Research by Baumgartner, Berry, Hojnacki, Kimball and Leech (2009) suggests a status quo bias for interest-group involvement in different policy areas with longstanding patterns of involvement in congressional policymaking. Given the endogenous relationship between the demand for expertise in policymaking and the development of it within the bureaucracy, Gailmard and Patty (2013) point to a differentiated use of the expertise provided by federal 
agencies. As such, there is plenty of reason to question the dominance of bureaucratic expertise.

In addressing this hypothesis, it is important to remember that not all information provision consists of expert advice about policy problems and solutions. The evidence for the dominance of bureaucratic expertise needs to show both greater frequency of information provision and expertise about problems or solutions. It also requires provision by agencies with purviews that are central to CIP.

\section{Issue differences and expertise}

(H2) : The demand for and supply of issue expertise differs among issues.

Two perspectives about how different types of expertise get drawn into policy debates are relevant. One is a supply-side perspective that suggests policymakers call upon regular networks of actors who have had sustained issue involvement over time. Those actors can be expected to differ among issue areas given the different issue niches of various groups (Kollman 1997; Baumgartner and Leech 2001). As such, the use of expertise can be expected to vary given historic differences in issue involvement among academics, bureaucracies, professional associations and think tanks. As the supply of expertise accumulates, by definition there is a greater store of knowledge about problems and solutions.

A second, demand-side perspective considers how groups are drawn into policy debates. From this perspective, groups and, by extension, different types of issue expertise are drawn into policy discussions, as issues gain prominence and have demonstrated material and other interest-specific consequences (see Gray, Lowery, Fellowes and Anderson 2005; Leech et al. 2005). This is also central to Bertelli and Wenger's (2009) explanation of the formation of think tanks as sources of expertise for policymaking. As issues demand attention, those with the largest stakes at hand are drawn into policy debates.

How these supply and demand considerations play out depends on the issues at hand. Long-standing, more salient issues will have engaged a diversity of interests and thus are more likely to have a ready supply of issue experts. Less salient issues will not have engendered sufficient demand to generate a diverse supply and thus are likely to have a more limited bullpen of issue expertise. As elaborated in our case discussion, we expect to see more extensive and broader issue expertise surrounding cyber-related CIP issues than CIP issues that are not cyber-related. The former issues have been more salient, fostering a greater demand for expertise that has resulted in deeper engagement of a range of industry and other groups. Because of the lower 
salience of the issues, issues that are not cyber-related are expected to have generated less extensive bases for issue expertise than cyber-related issues.

\section{Policymaking venues and hyper-expertise}

(H3) : Policy consistency is enhanced by repeat players across different venues.

Expertise is not necessarily a harmonising force that advances consistency in policymaking. Experts differ in their diagnosis of problems and prescriptions for solutions. Also, different categories of witnesses with different takes on problems and solutions are called upon to testify in different venues. Congressional committees have unique purviews and long-standing ties to actors who may not be policy-specific experts, but rather are committee-specific experts. As these individuals provide different ways of looking at problems and solutions, the involvement of an array of experts does not in itself lead to convergence on problems or solutions.

What then provides bases for consistent problem formulations and solutions? We view the realm of expert-based policymaking as including repeat players who are called upon in different venues and at different times to address the problem at hand. Such hyper-experts who are called upon to inform policymaking in multiple venues over time are key sources of policy convergence. This is particularly true when other voices provided by interest groups, state and local officials and so on are not present in policy debates. Hyper-experts gain a reputation as the go-to experts for issues related to specific policies over time because of their repeated appearances, further strengthening their role in defining and informing policymaking.

Our hypothesis suggests that hyper-experts who repeatedly inform policymaking over time are the glue holding policies together. However, this is not simply a function of the presence of hyper-experts. The type of information they offer policymakers is critical. Simply reporting about the current status of a problem or of efforts to address it provides a limited basis for coherent policy development. Hyper-experts who provide consistent views about policy problems and their solutions across different venues provide a stronger basis for coherent policy.

With respect to the CIP case, we expect hyper-experts for cyber-related CIP issues to be more evident than for CIP issues that are not cyber-related. Cyber infrastructure protection is more narrowly defined and has more specific stakeholders than physical infrastructure protection. The community of experts for cybersecurity includes a number of influential individuals and firms that form the basis for hyper-expertise. In contrast, the expertise for non-cyber CIP is more diffuse across a gamut of different types of 
physical infrastructures involving a wide range of different types of entities that own or manage infrastructure.

\section{Our case: CIP}

Problems surrounding CIP provide an instructive issue setting for considering issue expertise in policymaking. Our choice of this topic is the result of a research opportunity we had to consider the dynamics of policymaking for CIP as an example of a diffuse risk that presents numerous challenges for designing and implementing coherent policies. The public for CIP policy is largely non-existent. As a consequence, there are very few grassroots political demands from community and other interest-group stakeholders that typically influence public policy. Given this vacuum, issue experts who are normally drowned out or subsumed by organised interests are more relevant for policymaking.

At the same time, the susceptibility of the nation's physical and cyber infrastructure to attack, natural disaster or technological failure is a potential concern to a diverse set of financial firms, utilities, cyber-dependent businesses and infrastructure owners and managers. These concerns provide a basis for demands for information to address threats and a foundation for a supply of issue expertise beyond bureaucratic expertise.

The formal definition of critical infrastructure found in the USA PATRIOT Act (P.L. 107-56) is "systems and assets, whether physical or virtual, so vital to the US that their incapacity or destruction would have a debilitating impact on national security, national economic security, national public health or safety, or any combination of those matters". As suggested by this definition, critical infrastructures are very diffuse in that they span the country, entail many different sectors of activity and include a vast array of natural and human-caused risks of disruption. Threats to critical infrastructures broadly fit the notion of low salience policy issues given the dispersed nature of the risks, the inability to pinpoint likely disruptions in advance, the low probability of catastrophic events and the general lack of awareness among broader publics of the threats.

A distinction can be drawn between non-cyber-related CIP issues and cyber-related CIP issues. Non-cyber-related threats concern physical threats to critical facilities and infrastructure - bridges, railroads, airports, ports and so on - posed by human-caused disruptions, such as bombs or sabotage, along with disruptions from failed, aging infrastructure or natural catastrophes. The probability is so low that any one failure in critical infrastructure will directly affect particular individuals. Yet, the interdependence of the infrastructure systems ensures that small events can lead to broader consequences. While individual, catastrophic events like the 2007 collapse of 
the Mississippi River Bridge in Minneapolis, Minnesota draw media and public attention, broader issues concerning physical infrastructure are of low salience to mass publics. Public opinion polls after the introduction of the 2009 economic stimulus legislation showed strong support among the public for investing in infrastructure projects as a means of job creation. ${ }^{1}$ However, the foci of these polls was the economy rather than infrastructure per se.

Cyber-related CIP issues relate to computer-based network reliability and the network security of various industrial facilities, banking systems, utility systems and computer systems. The diffuseness of these risks and the limited understanding most people have about them contributes to the inattention of mass publics to these concerns. Yet, from time to time, the realities of threats to cybersecurity have impacted many individuals and have raised broader implications for the functioning of power grids, nuclear power plants, manufacturing and other critical systems. In these respects, the threats to cybersecurity have elements of individualised risk (e.g. individual computer outages) and diffuse risks (e.g. systems failures).

As more individuals have become aware of the potential harms to them, cybersecurity risks have been transformed over time from an issue with limited publics advocating for interventions to, at the time of our study, one with stronger interest engagement drawn mainly from the information industry. This evolution of interest involvement began with concerns about the Year 2000 (Y2K) computer transition and has occurred more recently with concerns about malware and widespread cyber attacks from foreign countries. The mass public salience of these issues is evident from the results of various public opinion polls. ${ }^{2}$ Some $40 \%$ of the respondents to a Gallup/CNN/USA Today poll in December 1999 thought there would be major problems in the new year as the result of the Y2K computer issue. Concerns about identify theft and banking were registered in polls as early as 1995. More than twothirds of respondents to a November 1995 Gallup/US News and World Report/CNN Poll reported they would be very worried about the security of their money if they banked by computer. By $2005,90 \%$ of respondents to a similar poll reported they are somewhat or very concerned about identity theft.

${ }^{1}$ We searched the Roper Center iPoll database for the period January 1995 through December 2009 using the term "infrastructure". The only polls referencing this were ones conducted after Hurricane Katrina in 2005 about the advisability of rebuilding damaged infrastructure and those in 2009 concerning support for investing in infrastructure projects as part of an economic stimulus package.

2 The following poll results were obtained from a search of the Roper Center iPoll database for the period January 1995 through December 2009 using terms "information security", "cybersecurity" and "computer security". Each of the polls was based on a national telephone sample of between 800 and 1,000 adults. 
In drawing the distinction between non-cyber and cyber-related issues, the CIP case is representative of the two realities that undergird our hypotheses. One, which fits non-cyber CIP, is of limited attention and development of sources of issue expertise. The second, which fits cyberrelated CIP, is greater attention and a fuller range of issue expertise.

\section{Research approach, data and measures}

We traced the involvement of different types of expertise in congressional hearings about CIP issues. We emphasised Congress as a policymaking venue for both theoretical and practical reasons. The theoretical reason is the role of Congress as a focal point for policymaking. The practical aspects relate to the ability to trace the role of different groups and types of experts in congressional hearings. Although congressional scholars disagree about the purposes of hearings, we argue that gaining consensus about problems and solutions is especially important for problems marked by high policy uncertainty. Kingdon (1981, 284-288) long ago noted that decisionmaking in Congress is motivated by a search for consensus in order to reduce each member's political and policy uncertainty (also see Krehbiel 1991, 66-70; Diermeier and Feddersen 2000; Sheingate 2006).

\section{Data for studying issue expertise}

We constructed data sets about issue expertise for critical infrastructure issues over the period 1995 through 2009. We chose 1995 as a starting point in order to reflect the increased attention to the threats to critical infrastructure that began in the mid-1990s following the 1993 World Trade Center bombing, the 1995 bombing of the Oklahoma City Murrah Federal Office building and the 1995 Tokyo subway nerve gas attack. President Clinton formed a commission to study critical infrastructure in 1996, and the President's Commission on Critical Infrastructure Protection issued its report in 1997. The end date for our data was dictated by the availability of transcripts of congressional hearings at the time of our data collection, which lag actual hearings in their production.

Our primary data are a coding of issue content and witness appearances at congressional hearings. Keyword searches were undertaken using the LexisNexis congressional hearing database. Our vocabulary was based on terminology employed as part of relevant government National Critical Infrastructure Protection plans (US Department of Homeland Security 2006, 2009), Congressional Research Service reports (Moteff 2010) and academic literature. This led to the identification of 19 keyword search terms. ${ }^{3}$

\footnotetext{
${ }^{3}$ The terms are as follows: critical infrastructure, information assurance, critical systems, infrastructure protection, infrastructure security, cyber crime, cybersecurity, physical security,
} 
This search initially yielded 750 hearings that included duplicates identified with multiple search terms. We first removed the duplicates and hearings by the 9/11 Commission that were unrelated to CIP. Recognising the imperfections of keyword searches, we next had research assistants evaluate each hearing for relevance to CIP, focusing on those hearings related to physical and virtual infrastructures that are essential for the functioning of society and the economy. ${ }^{4}$ This process also excluded hearings with general mentions of infrastructure, such as routine road improvements; hearings addressing general information security issues, such as identity theft; and hearings concerned with broader emergency management issues not explicitly dealing with the security of emergency management networks or some other aspect of critical infrastructure. We also excluded 38 appropriations-related hearings, since these did not deal with substantive issues around CIP and would bias expertise in favour of agency officials. The end result is a data set comprised of 204 hearings, including 162 held in the House, 39 held in the Senate and three joint hearings; $56 \%$ of the hearings addressed cybersecurity issues.

Using witness lists of those individuals who appeared at the hearings, we categorised the witnesses into different groups of interests. This approach to identifying witnesses has been employed by policy process scholars in studying agenda change (see Baumgartner and Jones 1993), interest-group alignments in different policy areas (see Worsham 2006) and the involvement of different interests in shaping policy in particular policy areas (see Miller 2004; Zafonte and Sabatier 2004). Although we recognise that congressional hearings are orchestrated and generally biased towards involvement of interests with established relationships (see Leyden 1995), these biases are central to our research in getting at the types of expertise that are involved in addressing issues for which broader publics do not exist.

We identified 1,151 witnesses appearing at the congressional hearings in our sample. Based on the witness titles and organisational affiliations, we categorised each individual according to a coding scheme that originally delineated 18 types of interests. ${ }^{5}$ For the analyses of issue experts that

facility security, technology security, computer security, internet security, information infrastructure, information security, chemical security, critical facilities, critical information systems, key assets and key resources.

${ }^{4}$ For the subset of 100 hearings that were scored by the same two coders, there was $87 \%$ agreement on whether the hearing should meet the minimum threshold of relevance before any clarifying discussion. After post-coding discussion, there was $98 \%$ agreement.

5 These were: local government, state government, experts and think tanks, business and industry firms, business and industry associations, governmental and other professional associations, public interest groups, individual testimony, House members or staff, Senate members or staff, special committee members, Congressional Research Service staff, General 
follow, we excluded congressional and special commission witnesses (16 individuals) and White House staff witnesses (23 witnesses), given that these types of witnesses had very different roles than our focus on issue expertise. This left 1,112 witness appearances for our analyses, recognising that some of the same witnesses appeared more than once.

Of these, we were able to obtain transcripts for 916 witness testimonies from the LexisNexis congressional database. We coded the content of testimonies with respect to the purpose of the testimony as having an informational, problem or solution focus; the specificity of the problem and solution focus, if present (general or specific treatment); and the extent to which a given testimony appeared to be self-serving, as in the case of a firm advocating for their products. We used this information to get at the nature of expertise and how it relates to problems and solutions for critical infrastructure issues.

\section{Measures}

Using these data sources, we derived the following sets of measures.

Hearing focus. Each hearing was coded as either focusing on cyber-related CIP issues or non-cyber-related CIP issues. We used this distinction to characterise differences in involvement of different sources of issues for the two issue areas.

Sources of issue expertise. This is a nominal classification of those who testified into five broad groups: federal agencies, state and local government, business and industry, non-business interests and research experts. This is a reclassification of our original coding of 18 categories of interest. We also categorised expertise from federal agencies as falling within the 11 categories of agencies listed below in our findings. We used these categorisations to show the distribution of witness appearances across different sources of expertise.

Issue-focused expertise. We considered expertise to be issue focused if a given testimony addressed a substantive problem, solution - or both, rather than simply providing information about what an agency or entity is doing with respect to a given problem. We classified testimonies as being issuefocused or not based on a coding of the content of witness testimonies.

Accountability Office staff, White House staff, Office of Management and Budget staff, members of Presidential commissions, inter-agency task forces and federal government agencies and independent entities. We calculated intercoder reliability for a subset of 161 witnesses, with $82 \%$ agreement among two coders for this classification and with 100\% agreement after discussion of the coding. 
Research assistants read each testimony and coded whether the majority of the testimony primarily concerned an informational, problem or solution focus. $^{6}$

Ranking federal officials. This is a nominal coding of federal bureaucrats who testified, distinguishing those who are of high rank from others. We designated ranking officials generally as those who were heads or deputy heads of agencies and, because of differences in agency structures, we designated specific titles for different types of agencies that constitute ranking titles. ${ }^{7}$

Hyper-expertise. We coded how many times a particular witness testified across all of the hearings in the data set. Those who testified multiple times were considered hyper-experts.

\section{Findings: issue expertise and policymaking}

We present findings regarding our hypotheses based on analyses of the data we collected for hearings about CIP issues that were held from 1995 through 2009. The analyses and discussion of findings are organised around each of the hypotheses. The unit of analysis for the first two sets of findings is a witness appearance, with attention to the types of witnesses. The unit of analysis for the third set of findings is each individual witness, with attention to the number of times each appears as a witness.

\section{Dominance of bureaucratic expertise}

Our findings about the involvement of different categories of issue experts in testifying about CIP issues are shown in Table 1. We draw an important distinction in the two columns of the table between who testifies (the distribution of witnesses) and what they testify about (issue-focused testimony). The latter consists of the percentage of those who specifically testified about aspects of the problem or solution, as opposed to more general testimony reporting what their agency or organisation has done to address aspects of CIP.

${ }^{6}$ For a sample of 50 witness testimonies, there was $84 \%$ agreement between coders for assignment to one of the three categories of testimony. There was $90 \%$ agreement between coders for designation of issue-focus (problem or solution) versus information provision.

${ }^{7}$ For large, cabinet-level agencies (e.g. treasury, Energy, HHS, State, DHS), Secretary, Deputy Secretary, Under Secretaries - or equivalent titles in agencies that use Assistant Secretary rather than Under Secretary (e.g. DoD, Energy) or that use the title Assistant more generally for this function (e.g. Justice). For smaller cabinet-level and independent agencies (e.g. EPA, FEMA before incorporation into DHS, FTC), Administrator or Director, Deputy Administrator or Deputy Director, Commissioners, Chairman. 
Table 1. Issue expertise

\begin{tabular}{|c|c|c|}
\hline Category & Percentage Distribution* & Percent Issue Focused $^{\dagger}$ \\
\hline Federal agencies & 37 & 19 \\
\hline Business and industry & 26 & 54 \\
\hline Research experts ${ }^{\ddagger}$ & 19 & 67 \\
\hline Non-business interests $\$$ & 13 & 76 \\
\hline State and local government & 5 & 35 \\
\hline Total/overall ${ }^{\mathrm{TI}}$ & 100 & 45 \\
\hline Number of witness appearances $\|$ & 1,112 & 916 \\
\hline
\end{tabular}

Source: Compiled by authors.

Notes: *Percentage distribution of witness appearances among the designated categories.

${ }^{\dagger}$ Percentage of those testifying with testimony that had a problem or solution focus rather than informational focus.

${ }^{\ddagger}$ Includes research and academic experts, consulting firms, think tanks and nongovernmental research organisations.

${ }^{\mathbb{S}}$ Includes governmental, professional and other associations and public advocacy groups.

IlTotal percentage of testimony with an issue focus.

$\|_{\text {Missing testimonies account for the difference in number of witnesses. }}$

Consistent with our first hypothesis about the dominance of bureaucratic expertise, as shown in the first column of Table 1, the major contributors to the discussion of CIP issues are federal agency personnel. This is in keeping with the previous findings about reliance upon bureaucratic information in congressional hearings. As CIP programmes are administered by and largely funded through the Department of Homeland Security, it is not surprising that federal personnel comprise the largest category of witnesses. Given the significance of cyber-related CIP issues to business and industry, it is also not surprising that representatives of firms and industry associations are relied upon relatively extensively to offer testimony. Curiously, representatives of state and local governments - identified in CIP planning documents authored by the US Department of Homeland Security (2006, 2009) as a key group for non-cyber-related CIP programmes - have relatively limited presence in CIP hearings.

A different picture emerges, however, when considering what witnesses testify about, as shown in the second column of Table 1 . Witnesses from nongovernmental entities have a much stronger issue focus on problems or solutions than those from the federal bureaucracy. Instead of assessing problems and offering solutions, our data show that governmental actors, be they federal, state or local personnel, largely provide information about existing 
programmes or descriptions of what their agencies are doing to address CIP problems. In contrast, the issue expertise provided by non-business interests (comprised mainly of representatives of governmental, professional and other associations) and research experts (comprised of research and academic experts, consulting firms, think tanks and non-governmental research organisations) dominates the substantive contributions to understanding problems and solutions. In a sense, the governmental personnel provide the broad context while the others provide the specifics.

Considering that the federal CIP partnership encompasses virtually all federal agencies (see US Department of Homeland Security 2006, 2009), the examination of testimony by personnel from different federal agencies provides a window into differences among federal agencies in the expertise they offer. As shown in Table 2, the preceding broad characterisation of witness appearances by personnel from federal agencies masks variation among these agencies. Here, we draw a distinction among the distribution of witnesses from different federal agencies, the percentage of those who testify who are ranking agency officials and the percentage of those who specifically testified about aspects of the problem or solution. We surmised from our review of testimonies that ranking officials were more likely to provide general testimony reporting on agency activities rather than more issue-focused testimony. This is evidenced by a Pearson correlation between the last two columns of -0.36 .

A notable finding is that witnesses from the Department of Homeland Security, who by far have the largest presence in congressional testimony, offer among the least issue-specific testimony. This also is the case for witnesses from the Department of Defense who tend to report on efforts to physically secure defense facilities and avert cyber attacks rather than suggest new problem diagnoses or new solutions. In contrast, nearly $50 \%$ of the testimony of personnel from the State Department, Treasury, General Services Administration and Justice Department is issue focused in addressing aspects of CIP problems or solutions.

While some of these results are artefacts of a small number of witness appearances (as for the General Services Administration), the differences in testimony are evident from our perusal of individual statements. Personnel from the Department of Homeland Security and the Department of Defense, including both top officials and programme personnel, tended to report on the status of CIP programme development and programmatic needs. In contrast, personnel providing issue-specific testimony from other agencies tended to draw attention to how threats to critical infrastructures present novel problems (e.g. national security issues for State Department officials, banking security for Treasury officials, safety of public facilities for the General Services Administration and privacy and other legal issues for the Justice Department) and require specific steps to mitigate those problems. 
Table 2. Federal-agency expertise

\begin{tabular}{|c|c|c|c|}
\hline Federal Agency & $\begin{array}{c}\text { Percentage } \\
\text { Distribution* }\end{array}$ & $\begin{array}{l}\text { Percent Ranking } \\
\quad \text { Official }^{\dagger}\end{array}$ & $\begin{array}{l}\text { Percent Issue } \\
\text { Focused }^{\ddagger}\end{array}$ \\
\hline Homeland security & 27 & 15 & 13 \\
\hline Justice & 12 & 6 & 46 \\
\hline Defense & 9 & 19 & 7 \\
\hline Energy & 9 & 29 & 35 \\
\hline Commerce & 6 & 44 & 17 \\
\hline State & 5 & 0 & 70 \\
\hline Transportation & 6 & 0 & 18 \\
\hline Treasury & 3 & 31 & 57 \\
\hline $\begin{array}{l}\text { General services } \\
\text { administration }\end{array}$ & 2 & 0 & 50 \\
\hline Other cabinet level ${ }^{\S}$ & 4 & 29 & 17 \\
\hline Other non-cabinet level ${ }^{\mathrm{gI}}$ & 16 & 22 & 27 \\
\hline $\begin{array}{l}\text { Total percentage/overall } \\
\text { Percent } \|\end{array}$ & 100 & 18 & 19 \\
\hline Number of cases** & 408 & 72 & 66 \\
\hline
\end{tabular}

Source: Compiled by authors.

Notes: *Percentage distribution of witness appearances among the designated categories for agencies with 10 or more witness appearances.

${ }^{\dagger}$ Percentage of witnesses from cabinet-level agencies with titles of Secretary, Deputy Secretary, Under Secretary or equivalent titles and from non-cabinet level and independent agencies with titles of Administrator or Director, Deputy Administrator or Deputy Director, Commissioner or Chairman.

${ }^{\ddagger}$ Percentage of those testifying with testimony that had a problem or solution focus rather than informational focus.

${ }^{\$}$ Includes Agriculture, Education, Health and Human Services, Interior and Labor.

IIIncludes Environmental Protection Agency, Federal Trade Commission, NASA, National Science Foundation, Nuclear Regulatory Commission, US Postal Service, CIA and NSA.

$\|$ For the last two columns, the total percentage of ranking officials among all witnesses and percent of testimony with an issue focus.

**Number of witness appearances and/or testimonies for relevant columns.

\section{Issues and expertise}

We hypothesise that the types of expertise called upon by policymakers varies based upon the extent to which there is an extant supply of experts or a demand for expertise. As explained above, we expect to see more extensive and broader issue expertise surrounding cyber-related CIP issues than non-cyber-related CIP issues. The former issues have been more salient, fostering a greater demand for expertise, and have a basis for a greater supply of business and industry engagement. 
Table 3. Cyber-versus non-cyber issue expertise

\begin{tabular}{lcc}
\hline \hline \multirow{2}{*}{ Categories } & \multicolumn{2}{c}{ Witness Percentage Distribution* } \\
\cline { 2 - 3 } & Cyber-Related Hearings & Non-Cyber-Related Hearings \\
\hline Federal agencies & 37 & 36 \\
Business and industry $_{\text {Research experts }}^{\dagger}$ & 31 & 20 \\
Non-business interests $^{\ddagger}$ & 21 & 16 \\
State and local government & 9 & 18 \\
Total & 2 & 11 \\
Number of witness appearances & 100 & 100 \\
Distribution comparison & 667 & \multicolumn{2}{c}{$\chi^{2}=66.87, \mathrm{p}<0.00$} \\
\hline \hline
\end{tabular}

Source: Compiled by authors.

Notes: "Percentage distribution of witness appearances among the designated categories for cyber- and non-cyber-related hearings.

${ }^{\dagger}$ Includes research and academic experts, consulting firms, think tanks and nongovernmental research organisations.

${ }^{\ddagger}$ Includes governmental, professional and other associations and public advocacy groups.

${ }^{\$}$ Comparison of the witness percentage distributions for cyber- and non-cyber-related hearings.

Table 3 displays the distribution of witness appearances for cyber- and non-cyber-related hearings. As with the overall findings reported above, federal agency personnel constitute the largest category of those testifying. ${ }^{8}$ Table 3 also displays evidence of the supply-side effects of cyber-related policymaking by showing a stock of business, industry and research experts for addressing cyber-related issues. The effects of a more diffuse demand for addressing non-cyber-related issues is evidenced by the wider distribution of witness appearances for this category of hearings. In comparison with the cyber-related hearings, we note the greater involvement of non-business and state and local government interests in non-cyber-related hearings.

Table 4 addresses differences in the content of testimony in drawing attention to the extent to which cyber- and non-cyber-related testimonies

${ }^{8}$ There were 247 witness appearances from federal agencies for cyber-related hearings and 161 witness appearances for non-cyber-related agencies. The $\chi^{2}$ test of differences in the distributions of witness appearances across agencies when categorised as in Table 2 is 49.36, $\mathrm{p}<0.00$. Non-cyber-related hearings were dominated by representatives from the Department of Homeland Security ( $40 \%$ of witness appearances), while witness appearances for federal agencies for cyber-related hearings were distributed more broadly across agencies. 
Table 4. Cyber-versus non-cyber issue foci

\begin{tabular}{lcc}
\hline \hline & \multicolumn{2}{c}{ Percent Issue-Focused Witness Testimonies* } \\
\cline { 2 - 3 } Categories & Cyber-Related Hearings & Non-Cyber-Related Hearings \\
\hline Research experts $^{\dagger}$ & 72 & 58 \\
Non-business interests $^{\ddagger}$ & 67 & 82 \\
Business and industry $_{\text {State and local government }}$ & 51 & 59 \\
Federal agencies & 33 & 35 \\
Overall $^{\S}$ & 17 & 22 \\
Number of witness testimonies & 44 & 47 \\
\hline \hline
\end{tabular}

Source: Compiled by authors.

Notes: *Percentage of those testifying with testimony that had a problem or solution focus rather than informational focus for cyber- and non-cyber-related hearings.

${ }^{\dagger}$ Includes research and academic experts, consulting firms, think tanks and nongovernmental research organisations.

${ }^{\ddagger}$ Includes governmental, professional and other associations and public advocacy groups.

${ }^{\$}$ Overall percentage of those testifying with testimony that had a problem or solution focus rather than informational focus.

deal with problems or solutions rather than simply report information about activities. Here, the main differences are the larger percentage of research experts providing issue-specific testimony for cyber-related issues and the larger percentage of non-business experts providing issue-specific expertise for non-cyber-related issues. The more extensive issue focus of experts for cyber-related issues is intuitive given the stronger supply of experts and the long-standing involvement in addressing these issues. The findings for non-business experts are, at first glance, more puzzling.

Digging into the specifics of some of the non-business related testimony helps to show what is involved. One example of issue-focused testimony from a non-business group comes from Danielle Brian, the executive director of the non-profit Project on Government Oversight. The mission of this group is to investigate government corruption and fraud, but the group also acts as a general watchdog on other governmental operations, such as safety. Ms. Brian called attention to specific problems related to the management of the federal protective service and vast amounts of overtime used at Department of Energy research facilities in a hearing held in 2005 before the subcommittee on National Security, Emerging Threats and International Relations. Other examples of detailed testimonies about problems and solutions concerning non-cyber-related issues by 
Table 5. Research expert witness testimony: cyber versus non-cyber

\begin{tabular}{lccc}
\hline \hline & \multicolumn{2}{c}{ Percentage Distribution of Witness Testimonies* } \\
\cline { 2 - 4 } Categories of Testimony & $\begin{array}{c}\text { Cyber-Related } \\
\text { Hearings }\end{array}$ & $\begin{array}{c}\text { Non-Cyber-Related } \\
\text { Hearings }\end{array}$ & $\begin{array}{c}\text { All } \\
\text { Hearings }\end{array}$ \\
\hline Informational $^{\dagger}$ & 28 & 42 & 33 \\
Problem oriented $^{\ddagger}$ & 48 & 31 & 42 \\
Solution oriented $^{\$}$ & 25 & 27 & 26 \\
Totals $_{\text {Number of witness }}$ & 100 & 100 & 100 \\
$\quad$ testimonies & 109 & 59 & 168 \\
Distribution comparison & & & \\
\hline \hline
\end{tabular}

Source: Compiled by authors.

Notes: "Percentage distribution of witness testimonies among the designated categories of testimony for cyber- and non-cyber-related hearings.

${ }^{\dagger}$ Reporting about the activities, efforts or nature of work of a given agency, organisation, association or firm.

${ }^{\ddagger}$ Calling attention to the vulnerabilities, concerns or other aspects of critical infrastructure or cyber-related problems.

${ }^{\$}$ Suggesting ways for addressing the vulnerabilities, next steps to be taken, revisions to proposed legislation, needed actions, changes in roles or other aspects of solutions. ${ }^{\mathrm{II}}$ Comparison of the percentage distributions for cyber- and non-cyber-related hearings.

non-business interests are provided by the testimonies of the President of the Airline Pilots Association International regarding TSA screening procedures and a representative of the US Public Interest Research Group questioning specific components of infrastructure protection related to chemical facilities.

A different way of considering issue differences is a comparison of the testimonies of the traditional category of research experts - academic experts, consulting firms, think tanks and non-governmental research organisations who constitute a primary source of issue-focused expertise. Table 5 shows the distributions of the content of testimony by these experts while taking into account differences in cyber- and non-cyber-related testimonies.

Two sets of findings are of interest in this table. One, as shown in the first column, is the greater frequency of problem-oriented testimony for cyberrelated hearings. This likely reflects the generally emergent and changing nature of the concerns about cyber issues for which grappling with the nature of the problem is foremost. In contrast, a second key finding shown in the middle column is that witnesses at non-cyber-related hearings tend to 
emphasise information provision. Our reading of testimonies shows this consists of reporting on an entity's activities or providing broader commentary about the efforts of the research and academic community to study infrastructure failures. Given the greater frequency of cyber-related hearings, the problem-oriented focus, shown in the last column, is the dominant one for testimonies by research experts. However, as this table shows, the overall finding masks differences in the maturity and salience of issues - two sets of considerations that shape the content of witness testimonies.

\section{Venues and hyper-expertise}

A small but important segment of expertise concerns those individuals who testify in multiple hearings across subcommittees, over time with the same committee, or both. Such hyper-expertise is important as a way of providing consistent messages about problems and potential solutions for complex problems like CIP. In all, $80 \%$ of all witnesses who testify about CIP issues only testify once. Typically, a witness is brought in to describe a problem, solution or what is currently being done with respect to the issue discussed at the hearing and is not seen again for that or other hearings. This pattern is particularly evident for the state and local government category, with $86 \%$ of those witnesses only appearing once. This demonstrates the episodic involvement of this interest community for which there is little basis for a consistent position. Federal agency witnesses are not far behind, with $75 \%$ appearing only once and $17 \%$ appearing twice.

Less than $5 \%$ of witnesses in a given category testify more than three times, with the notable exception of research experts. A total of $9 \%$ of the witnesses in the research expert category testified on three or more occasions and $7 \%$ testified on five or more occasions. These witnesses included several academics and think tank experts. One notable expert, Richard Pethia, is a professor at the CERT Center at Carnegie Mellon University. ${ }^{9}$ Pethia's 10 testimonies before committees between 1996 and 2003 focus primarily on emerging cyber threats, such as the Melissa worm, and recommending steps government should take in order to keep the nation's critical infrastructure secure. Pethia brings a consistent message of the urgent need to invest in additional cybersecurity to each hearing and seems to have become a trusted source for detailed information about the impact of the many computer viruses and worms since cyber threats were just beginning to emerge.

\footnotetext{
${ }^{9}$ Originally standing for computer emergency response team, CERT, a trademark of Carnegie Mellon University, is no longer an acronym (http://www.cert.org/faq/cert_faq.html\#A3).
} 
The only other witness category with a significant proportion of repeat witnesses is business and industry, for which $3 \%$ of witnesses appeared in five or more hearings. These individuals represent well-known technology companies including eBay, Microsoft and VeriSign, as well as technology and financial services industry groups. One prominent group is BITS, which is part of the Financial Services Roundtable. ${ }^{10}$ Catherine Allen, the CEO of BITS, testified eight times between 1999 and 2007. Four other business representatives also testified on behalf of BITS. More than half $(62 \%)$ of testimony by BITS representatives was issue focused.

As anticipated, we find more hyper-expertise in cyber-related hearings than non-cyber-related hearings. In all, $75 \%$ of testimonies from witnesses appearing more than three times are for cyber-related hearings. The non-cyber hearings address a more diffuse set of issues for which the vast majority of repeat witnesses are Department of Homeland Security officials. The non-cyber CIP issues include security at Department of Energy facilities, power plants, transportation security, water security and more. Across this diverse set of topics, the issues vary widely and there is less opportunity for experts to aggregate the concerns in a consistent way.

These findings illustrate the influence of a small cadre of hyper-expertise in drawing attention to problems and solutions. Although there is an overall lack of continuity across witnesses among the hearings we study, several hyper-experts emerge from the expert and business and industry witness categories. These individuals and the organisations they represent supply a consistent message to congressional committees about the relevance and importance of cybersecurity concerns.

\section{Conclusions}

We have addressed the extent to which the bureaucracy has a privileged role as an information conduit, how issue differences affect sources of expertise and how expertise is distributed across different venues. Our data are drawn from congressional hearings for CIP policymaking in the US between 1995 and 2009. The public for this issue area is largely nonexistent, and thus the federal government has very few political demands from community and other stakeholders that typically shape public policy. In this vacuum, issue experts who may be drowned out or subsumed by advocacy organisations can be expected to hold sway. The comparison of non-cyber and cyber-related critical infrastructure issues provides a basis for examining differences in the demand for and supply of expertise.

\footnotetext{
${ }^{10}$ Although originally standing for Banking Industry Technology Secretariat, BITS is no longer an acronym (http://www.bits.org/about/index.php).
} 
Three findings stand out from our research. The first concerns the presumed privileged role of the bureaucracy as an information conduit for policymaking. With the rise of advocacy organisations, think tanks, professional organisations and other information sources, scholars have questioned the centrality of bureaucratic expertise (Durant 1991; Rourke 1991). Our findings show that federal agency personnel are the major contributors to testimony about critical infrastructure issues, with other sources of expertise drawn from academic settings, industry, professional associations and think tanks. However, much of what federal government personnel testify about when called upon by Congress is informational. In contrast, expertise provided by non-business interests and research experts dominates the substantive contributions to understanding problems and solutions.

This set of findings cuts two ways. It reinforces the role of the bureaucracy as an information conduit. However, it also suggests that the bureaucracy is not necessarily a primary source of issue expertise. Although we find differences among witnesses from different agencies, federal witnesses and members of Congress tend to treat agency testimony as reporting for the purpose of oversight rather than as an opportunity to inform future policy. This is especially the case for testimony by agency ranking officials. This finding challenges the conventional view of the bureaucracy as the primary source of expertise in policymaking. For this case at least, governmental personnel seem to set the broad context while other sources of expertise provide the necessary problem and solution details.

A second set of findings concerns the demand for and supply of issue expertise. Given the greater salience of cyber-related issues and the more direct industry-related impacts of cyber threats, we find, as expected, greater degrees of business and industry involvement as witnesses for cyberrelated hearings than for non-cyber-related hearings. In comparison with cyber-related hearings, we note greater involvement for non-cyber-related hearings of non-business and state and local government interests. As might be expected, a larger percentage of research experts provided issue-specific testimony for cyber-related issues. Given the generally emergent and changing nature of the concerns about cyber issues for which grappling with the nature of the problem is foremost, the testimony of these research experts concerned the nature of the problem as opposed to suggesting specific solutions or broader information. This set of findings shows how differences in issue maturity and salience affect the demand for and supply of expertise.

A third set of findings concerns those individuals who testify in multiple hearings across subcommittees, over time with the same committee, or both. We suggest such hyper-expertise is important as a way of providing a consistent message about the problems and potential solutions for 
complex problems. This phenomenon is relatively rare for the issues we study, with $95 \%$ of witnesses testifying fewer than three times. Exceptions include some research and industry experts who testified multiple times across different committee venues concerning cyber-related critical infrastructure issues. These witnesses include several academics and individuals who represented well-known technology companies and technology and financial services industry groups. This set of findings illustrates the influence of a small cadre of hyper-expertise in drawing attention to problems and solutions.

An obvious issue is the degree to which these findings can be generalised beyond the case of CIP. We suggest that this issue area is similar to other "public risks" for which threats are widespread and that have prospective effects that are less apparent, are not easily comprehended and are not readily addressed by individual actions (see Huber 1986). Such risks do not engender public demands for action, have limited development of advocacy organisations calling attention to problems and require policymakers to incur up-front costs for delayed and uncertain benefits. There is not much of a constituency pushing for efforts to reduce these risks beyond experts within relevant policy communities (see Birkland 1997, 36-41). Examples of these include the loss of biological diversity, declining ocean health, threats to cybersecurity and other critical infrastructures and the potential catastrophic effects of earthquakes, volcanoes, tsunamis and other lowprobability natural events.

Our research contributes to the understanding of the role of the bureaucracy in policymaking. Additional empirical study of bureaucratic expertise in diverse policy arenas has the potential for further advancing the understanding of this role. Notable examples of this line of inquiry are recent scholarship by Gailmard and Patty (2013) and by Workman (2014). These provide new avenues for empirically examining the role of the bureaucracy as an information conduit in policymaking. Moving beyond a focus on issues of bureaucratic control to those of the supply of and demand for bureaucratic expertise reinvigorates thinking about the capacity of government to grapple with diverse problems.

Ultimately, the important considerations are what different types of issue expertise bring to the table and how that influences policymaking. These are central aspects of the political economy of policy expertise for which Kevin Esterling $(2004,73)$ frames the issue as "whether Congress can learn from public debate among interest groups about the likely effectiveness of policies or whether the interest groups will only exploit their informational advantage to confuse and mislead Congress". We found no evidence of policy obfuscation, perhaps because of the less value-laden nature of the issues we studied. Yet, our findings suggest that federal agency personnel are limited to a large 
degree in addressing basic questions about whether a policy should be created or about policy design. Other sources of expertise need to be relied upon for this advice. This may skew information provision in favour of business and industries that stand to gain the most from new policies. What we observe may be as much about the roles different information sources fulfil in the drama of policymaking as it is about the substance of policymaking.

\section{Acknowledgements}

Research assistance has been provided by Ashley Jochim, Barry Pump, Emma Tessier, and Breck Wilmot of the University of Washington, and by Mackenzie Fuller of Reed College. Financial support for this research was provided by National Science Foundation grant numbers CMMI-0924227 (Koski, PI) and CMMI-0925306 (May, PI). Neither the NSF nor those who have offered insights are responsible for the content of this article. We thank the anonymous reviewers and Anthony Bertelli, as Editor of the journal, for their advice.

\section{References}

Baumgartner F. R., Berry J. M., Hojnacki M., Kimball D. C. and Leech B. L. (2009) Lobbying and Policy Change: Who Wins, Who Loses, and Why. Chicago: University of Chicago Press.

Baumgartner F. R. and Jones B. D. (1993) Agendas and Instability in American Politics. Chicago: University of Chicago Press.

Baumgartner F. R. and Leech B. L. (2001) Interest Niches and Policy Bandwagons: Patterns of Interest Group Involvement in National Politics. The Journal of Politics 63(4): 1191-1213.

Bertelli A. M. and Wenger J. B. (2009) Demanding Information: Think Tanks and the US Congress. British Journal of Political Science 39(2): 225-242.

Birkland T. A. (1997) After Disaster: Agenda Setting, Public Policy, and Focusing Events. Washington, DC: Georgetown University Press.

Christensen J. (2012) Bringing the Bureaucrats Back In: Neo-Liberal Tax Reform in New Zealand. Journal of Public Policy 32(2): 141-168.

Diermeier D. and Feddersen T. J. (2000) Information and Congressional Hearings. American Journal of Political Science 44(1): 51-65.

Durant R. F. (1991) Whither Bureaucratic Influence?: A Cautionary Note. Journal of Public Administration Research and Theory 1(4): 461-476.

Esterling K. M. (2004) The Political Economy of Expertise. Ann Arbor: University of Michigan Press.

Gailmard S. and Patty J. W. (2013) Learning While Governing: Expertise and Accountability in the Executive Branch. Chicago: University of Chicago Press.

Gray V., Lowery D., Fellowes M. and Anderson J. L. (2005) Legislative Agendas and Interest Advocacy: Understanding the Demand Side of Lobbying. American Politics Research 33(3): 404-434.

Hall R. L. and Deardorff A. V. (2006) Lobbying as Legislative Subsidy. American Political Science Review 100(1): 69-84. 
Howlett M. (2009) Policy Analytical Capacity and Evidence-Based Policy-Making: Lessons from Canada. Canadian Public Administration 52: 153-175.

Huber P. W. (1986) The Bhopalization of American Tort Law. In National Academy of Engineering. (ed.), Hazards: Technology and Fairness. Washington, DC: National Academy Press, 89-110.

Jones B. D. and Baumgartner F. M. (2005) The Politics of Attention: How Government Prioritizes Problems. Chicago: University of Chicago Press.

Keller A. C. (2009) Science and Environmental Policy: The Politics of Objective Advice. Cambridge: MIT Press.

Kingdon J. W. (1981) Congressmen's Voting Decisions, 2nd ed. New York, NY: Harper and Row.

Kollman K. (1997) Inviting Friends to Lobby: Interest Groups, Ideological Bias, and Congressional Committees. American Journal of Political Science 41(2): 519-545.

Krehbiel K. (1991) Information and Legislative Organization. Ann Arbor: University of Michigan Press.

Lee J. (2013) The Administrative Broker: Bureaucratic Politics in the Era of Prevalent Information. The American Review of Public Administration 43(6): 690-708.

Leech B. L., Baumgartner F. R., La Pira T. M. and Semanko N. A. (2005) Drawing Lobbyists to Washington: Government Activity and the Demand for Advocacy. Political Research Quarterly 58(1): 19-38.

Leyden K. M. (1995) Interest Group Resources and Testimony at Congressional Hearings. Legislative Studies Quarterly 20(3): 431-439.

May P. J. (1991) Reconsidering Policy Design: Policies and Publics. Journal of Public Policy 11(part 2): 187-206.

Miller L. L. (2004) Rethinking Bureaucrats in the Policy Process: Criminal Justice Agents and the National Crime Agenda. Policy Studies Journal 32(4): 569-588.

Montpetit É. (2011) Scientific Credibility, Disagreement, and Error Costs in 17 Biotechnology Policy Subsystems. Policy Studies Journal 39(3): 513-533.

Moteff J. (2010) Critical Infrastructures: Background, Policy, and Implementation, CRS Report RL 30153. Washington, DC: Congressional Research Service.

Palus C. K. and Yackee S. W. (2013) Oversight as Constraint or Catalyst? Explaining Agency Influence on State Policy Decision Making. The American Review of Public Administration 43(3): 273-291.

Rourke F. E. (1991) American Bureaucracy in a Changing Political Setting. Journal of Public Administration Research and Theory 1(2): 111-129.

Sheingate A. D. (2006) Structure and Opportunity: Committee Jurisdiction and Issue Attention in Congress. American Journal of Political Science 50(4): 844-859.

US Department of Homeland Security (2006) National Infrastructure Protection Plan. Washington, DC: DHS.

(2009) National Infrastructure Protection Plan. Washington, DC: DHS.

Weible C. M. (2008) Expert-Based Information and Policy Subsystems: A Review and Synthesis. Policy Studies Journal 36(4): 615-635.

Workman S. (2014) The Dynamics of Bureaucracy in the U.S. Government: How Congress and Federal Agencies Process Information and Solve Problems. New York, NY: Cambridge University Press in press.

Workman S., Jones B. D. and Jochim A. E. (2009) Information Processing and Policy Dynamics. Policy Studies Journal 37(1): 75-92.

Worsham J. (2006) Up in Smoke: Mapping Subsystem Dynamics in Tobacco Policy. Policy Studies Journal 34(3): 437-452.

Zafonte M. and Sabatier P. A. (2004) Short-Term Versus Long-Term Coalitions in the Policy Process: Automotive Pollution Control, 1963-1989. Policy Studies Journal 32(1): 75-107. 